\title{
Scanning electron microscope-cathodoluminescence (SEM-CL) imaging of planar deformation features and tectonic deformation lamellae in quartz
}

\author{
M. F. HAMERS* and M. R. DRURY \\ Department of Earth Sciences, Faculty of Geosciences, Utrecht University, Budapestlaan 4, 3584 CD, Utrecht, The Netherlands \\ *Corresponding author. E-mail: hamers@geo.uu.nl
}

(Received 08 December 2010; revision accepted 26 September 2011)

\begin{abstract}
Planar deformation features (PDFs) in quartz are essential proof for the correct identification of meteorite impact structures and related ejecta layers, but can be confused with tectonic deformation lamellae. The only completely reliable method to demonstrate the shock origin of suspected (sub-) planar microstructures, transmission electron microscope (TEM) observations, is costly and time consuming. We have used a cathodoluminescence (CL) detector attached to a scanning electron microscope (SEM) to image both PDFs and tectonic deformation lamellae in quartz to demonstrate the potential of a simple method to identify PDFs and define characteristics that allow their distinction from tectonic deformation lamellae. In both limited wavelength grayscale and composite color SEM-CL images, PDFs are easily identified. They are straight, narrow, well-defined features, whereas tectonic deformation lamellae are thicker, slightly curved, and there is often no clear boundary between lamella and host quartz. Composite color images reveal two types of CL behavior in PDFs: either they emit a red to infrared CL signal or they are nonluminescent. The color of the CL signal emitted by tectonic deformation lamellae ranges from blue to red. For comparison, we also imaged several shocked quartz grains at cryogenic temperature. In most cases, the PDF characteristics in cryo-CL images do not differ significantly from those in images recorded at room temperature. We conclude that SEM-CL imaging, especially when color composites are used, provides a promising, practical, low cost, and nondestructive method to distinguish between PDFs and tectonic lamellae, even when the simplest CL techniques available are used.
\end{abstract}

\section{INTRODUCTION}

Shock metamorphism in terrestrial minerals is diagnostic of meteorite impacts. The presence of shockmetamorphosed quartz, in particular, is essential for the correct identification of impact craters and distal ejecta layers. As quartz displays a wide array of shock features and is one of the most abundant and most stable minerals in the Earth's crust, shock metamorphism in quartz has been extensively studied in both natural and experimental settings (e.g., Engelhardt and Bertsch 1969; Kieffer et al. 1976; Goltrant et al. 1992; Gratz et al. 1992; Langenhorst 1994; Langenhorst and Deutsch 1994; Leroux et al. 1994; Stöffler and Langenhorst 1994; Grieve et al. 1996;
Trepmann and Spray 2005; Trepmann 2008). Shock features in quartz comprise mosaicism, planar fractures (PFs), planar deformation features (PDFs) or shock lamellae, high pressure polymorphs (coesite and stishovite), diaplectic glass, and lechatelierite. Recently, feather features (French et al. 2004; Poelchau and Kenkmann 2011) and ballen silica (Ferrière et al. 2009, 2010) have been proposed as additional shock indicators. PDFs are the most widely studied and most easily recognized shock features that form in quartz. They can be recognized as multiple sets of thin, very closely spaced $(<2 \mu \mathrm{m})$ sets of planar features that develop parallel to rational low index crystallographic planes, of which the most frequent orientations are (0001), \{10 $\overline{3}\}$ and $\{10 \overline{1} 2\}$ 
(e.g., Grieve et al. 1996). PDFs can be subdivided into nondecorated (fresh) and decorated (annealed) types. Fresh PDFs are thin, amorphous lamellae, whereas older structures are annealed or recrystallized, and can usually only be recognized as traces of microscopic fluid inclusions. PDFs parallel to (0001) are not amorphous lamellae, but mechanical Brazil twins (Goltrant et al. 1992), and unless they are annealed and decorated, they cannot be resolved in the optical microscope. Often multiple (max. 18) sets of PDFs develop in a single quartz grain, with the number of sets per grain increasing as a function of shock pressure. PDFs are usually penetrative through a whole grain, but do not cut across grain boundaries, fractures or planar fractures, unless these form at a later stage than the PDFs. A thorough review of shock metamorphic effects in quartz is given in Stöffler and Langenhorst (1994) and Grieve et al. (1996).

As PDFs are such important features of impact evidence, their correct identification is crucial. However, using a standard petrographic microscope, it can be difficult to distinguish between PDFs and nonshockrelated planar microstructures in quartz. On several occasions, lamellar microstructures in quartz have been identified as PDFs, but have subsequently been disproved to be shock-related, or they remain controversial (e.g., Vrána 1987 versus Cordier et al. 1994; Surenian 1988 versus Leroux and Doukhan 1993; Ernstson and Fiebag 1992 versus Langenhorst and Deutsch 1996; Becker et al. 2004 versus Glikson 2004; Retallack et al. 1998 versus Langenhorst et al. 2005). Tectonic deformation lamellae, in particular, are often confused with PDFs, even though these two types of microstructure are fundamentally different in character. Tectonic deformation lamellae are more or less planar features that form in quartz grains as a result of comparatively slow, tectonic processes. When decorated with fluid inclusions, they are also known as Böhm lamellae (Böhm 1883; Christie and Raleigh 1959). Similar to PDFs, tectonic deformation lamellae are restricted to single grains and do not cross grain boundaries or fractures that formed before the lamellae. Tectonic deformation lamellae are often recognized in transmission electron microscopy (TEM) as slight misorientations in the crystal lattice; elongated, extremely narrow subgrains; arrays of fluid inclusions; subgrain walls; and zones of different dislocation density (White 1973; Drury 1993; Vernooij and Langenhorst 2005). Usually, a maximum of two sets develops in a sub-basal orientation (Drury 1993). Although recently, the term "Metamorphic Deformation Lamellae" was used in a review paper by French and Koeberl (2010), we will retain the term "tectonic deformation lamellae," which is more widely used in the literature. In general, tectonic lamellae are thicker, more widely spaced, and more curved than PDFs, but the two types of structure can be remarkably similar in appearance in a light microscope (Fig. 1; see also for example Officer and Carter 1991; Lyons et al. 1993; Fig. 2c in Vernooij and Langenhorst (2005), or Fig. 29 and 30 in French and Koeberl (2010)). As a result of their apparent similarity, TEM observations of the microstructures are required to convincingly demonstrate the shock origin of lamellar microstructures in quartz (Leroux et al. 1994; Cordier and Gratz 1995; Vernooij and Langenhorst 2005). However, TEM analysis can only be done on very small sample volumes, is time consuming and costly, and TEM facilities are not easily accessible to many research groups. Scanning electron microscopy (SEM) observations, on the other hand, are quick, and nowadays many groups have access to an SEM instrument. Observations can be done on relatively large specimens, and standard polished thin sections can be handled without difficulties. This is a great advantage, as it enables direct comparison to light microscopy. For example, the same thin section could be used to obtain statistically significant universal stage orientation data to estimate shock pressures. Using a TEM, the same type of measurements can only be made on a few grains. Therefore, reliable SEM methods to identify PDFs in quartz would form a welcome addition to TEM observations. Furthermore, SEM techniques are nondestructive, which is a great advantage in the study of shocked minerals.

Gratz et al. (1996) already showed that etching techniques and secondary electron (SE) imaging provide an unambiguous criterion for distinction of PDFs and tectonic deformation lamellae: amorphous PDFs etch out when treated with $\mathrm{HF}$ acid; tectonic deformation lamellae, in contrast, do not exhibit such well-developed etching patterns (Wegner and Christie 1983). Cathodoluminescence (CL) imaging, both in light microscopy and in an SEM, is a technique that has been used to image shocked quartz grains in general (Ramseyer et al. 1992; Trepmann et al. 2005) and PDFs in quartz in particular (Seyedolali et al. 1997; Boggs et al. 2001; Gucsik et al. 2003; Cavosie et al. 2010), but no comparison of PDFs with tectonic deformation lamellae has been made. Seyedolali et al. (1997) used CL to determine the provenance of quartz grains from different settings, including impact sites and stratigraphic impact layers. They found that PDFs can be imaged using a CL detector attached to an SEM, although Gucsik et al. (2003) did not report PDFs in SEM-CL images of experimentally shocked quartzites. Cavosie et al. (2010) imaged shocked quartz grains from the Vredefort crater, showing that basal (Brazil twin type) PDFs can also be observed with SEM-CL. Boggs et al. (2001) used SEM-CL methods to show that in CL images, PDFs can be distinguished from healed tectonic microfractures, but this is the only tectonic structure they looked at, and they did not consider tectonic 

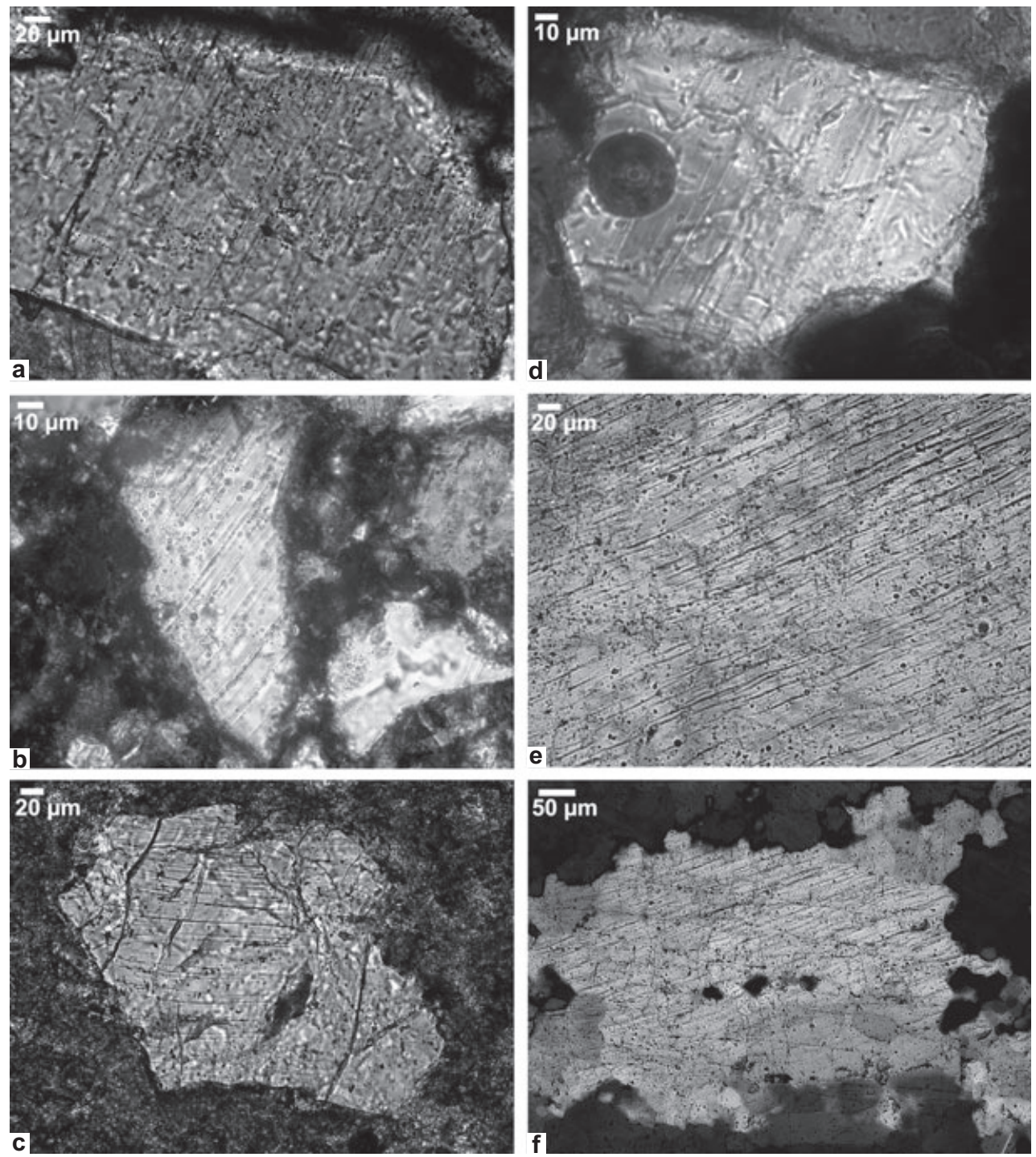

Fig. 1. Light microscopic images of PDFs in grains from Vredefort (a), Rochechouart (b and c), and of tectonic deformation lamellae from Flinders Ranges, Australia (d), and the Belgian Ardennes (e and f). Especially the PDFs from Vredefort (a) and tectonic deformation lamellae from Flinders Ranges (d) look similar on first inspection. Images a, b, c, and f are taken with crosspolarized light; images $\mathrm{c}$ and e with plane-polarized light.

deformation lamellae. We used SEM-CL imaging techniques, both grayscale (limited wavelength) and composite color, to study known examples of PDFs and of tectonic deformation lamellae in quartz to define characteristics that can be used to identify PDFs and distinguish them from other, nonshock-related lamellar microstructures. In this article, we primarily aim to provide an easy, low-cost method to reliably distinguish between PDFs and tectonic deformation lamellae and not to explain the CL behavior of the structures in detail, but some possible interpretations of the CL emission of PDFs will be discussed.

\section{SAMPLES AND METHODS}

\section{Samples and Imaging Techniques}

Two SEM systems, each equipped with a CL detector, were used to record CL images in this study. Both systems are located at the Electron Microscopy Laboratory at Utrecht University in the Netherlands. The first system is a Philips XL30S FEG SEM equipped with a Centaurus CL detector (K.E. Developments Ltd, Cambridge, UK), which has a wavelength detection range of $300-650 \mathrm{~nm}$ with a peak at $420 \mathrm{~nm}$, and is 

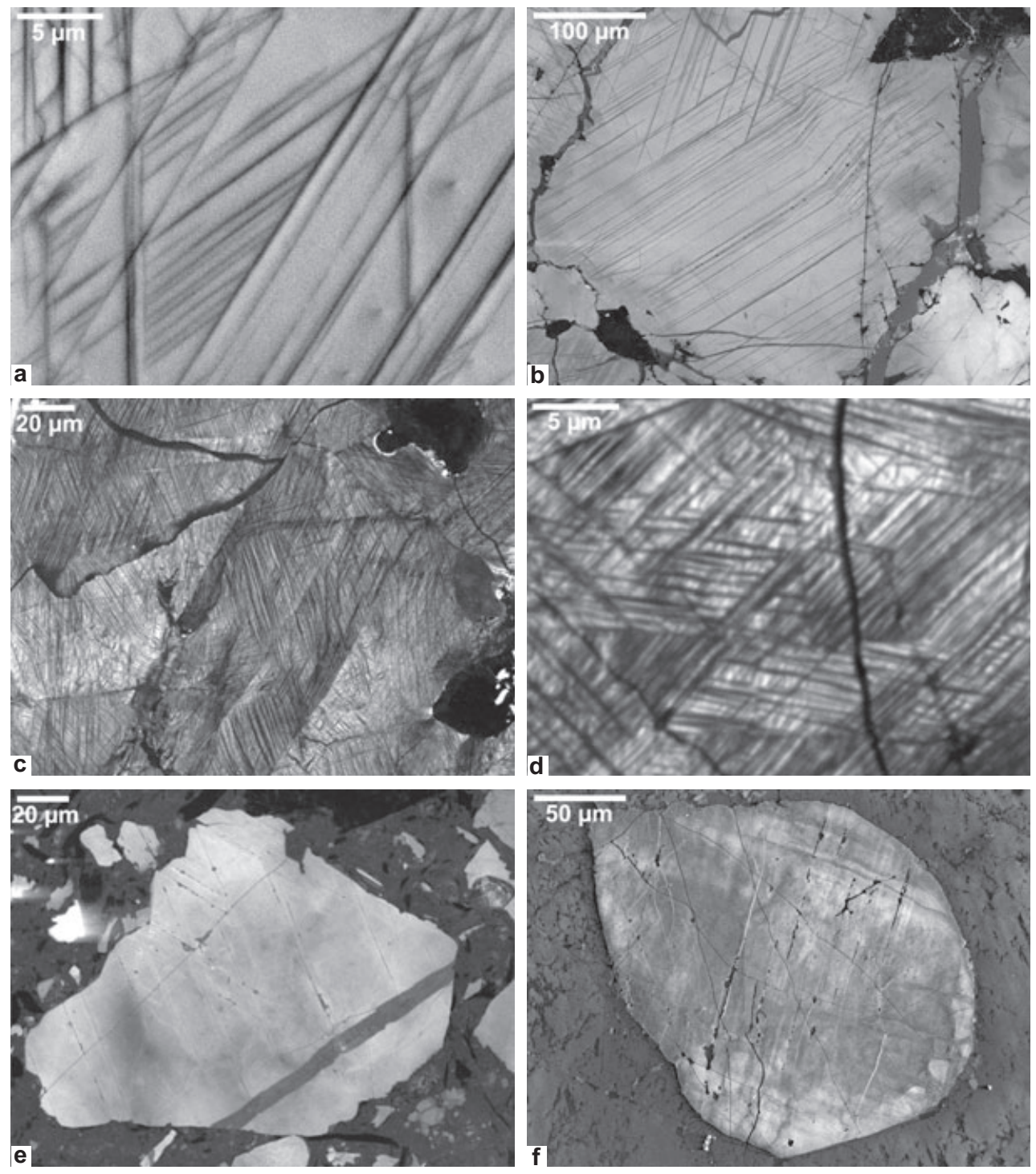

Fig. 2. Limited wavelength CL images of PDFs from the Ries (a-d), Rochechouart (e), and Vredefort (f) impact structures. PDFs are visible in the Ries and Rochechouart samples, but in the Vredefort sample, they can only be recognized from the traces of holes or fluid inclusions. The semi-linear features in the top of the Vredefort grain (f), running NE-SW, are not PDFs, and are not visible in the light microscope.

thus most sensitive to blue to violet light. In addition, the samples were studied in an FEI Nova Nanolab 600 SEM with Gatan PanaCL detector (Gatan UK, Oxford, UK). The PanaCL detector is more or less panchromatic, and has a detection range of $185-850 \mathrm{~nm}$. Three color filters (red, green, and blue) can be fitted to the Gatan detector for recording color filtered images. The red filter primarily transmits light in the range $595-850 \mathrm{~nm}$, the green filter in the range 495-575 nm, and the blue filter in the range 185$510 \mathrm{~nm}$. Both unfiltered and filtered images were recorded; the filtered images were subsequently combined into composite RGB color images in Adobe Photoshop, by including them in the red, green, and blue channels of a new image file. As red, green, and blue channels were optimized individually to obtain the maximum amount of information from the image, color information in the images is nonquantitative. The instruments were operated at an acceleration voltage of $5-10 \mathrm{kV}$ and with a beam current of 1.6-6.3 nA, at room temperature. For comparison, 10 shocked quartz grains were also imaged at cryogenic temperatures, between $-140{ }^{\circ} \mathrm{C}$ and $-170{ }^{\circ} \mathrm{C}$, using a liquid nitrogen-cooled cryostage in the Nova Nanolab 600 SEM with color filtered CL. In addition to the CL images, SE and, for most grains, light microscopic images were recorded. All samples are standard polished thin sections, which were carbon coated to prevent charging. 
Grayscale (limited wavelength) CL images were recorded using the Centaur CL detector for 57 shocked quartz grains in eight samples from well-known impact structures that have been extensively studied (Ries, Rochechouart, Popigai, and Vredefort), and for nine grains in one sample containing tectonic deformation lamellae from the Flinders Ranges, Australia. For color CL, using the Gatan PanaCL detector, 51 quartz grains containing PDFs were studied in 13 different samples from the same impact structures. Six grains from the Ries crater and four grains from the Popigai crater were also imaged at temperatures between $-140{ }^{\circ} \mathrm{C}$ and $-170{ }^{\circ} \mathrm{C}$. Furthermore, 27 grains with tectonic deformation lamellae were studied in six samples from three locations (Flinders Ranges, Australia; the Belgian Ardennes; and Cantabria, Spain). These numbers are summarized in Table 1. In several cases, the same grains were studied with the two different SEM-CL systems for comparison.

Although the Flinders Ranges in the Adelaide Fold Belt, from which the Australian deformation lamellae samples were taken, is within the range of the ejecta layer of the Late Neoproterozoic Acraman impact structure (Williams and Gostin 2005), we are quite certain that the samples do not come from this impact layer. The samples were taken from massive quartzite layers such as the $\mathrm{ABC}$ quartzite, whereas the impact ejecta are found in the Bunyeroo mudstone formation.

\section{Cathodoluminescence Background}

When an electron beam hits a sample in an SEM, several types of beam-sample interaction can occur. One result is that electrons can be excited to a higher energy level. When excited electrons fall back to their original state, either directly or via a trap (in the form of a lattice defect, impurity, or vacancy), photons can be emitted with energies in the infrared, visible, or ultraviolet wavelength ranges. This photon emission is the basis of CL. The wavelength (and thus the color) and intensity of the emitted photons vary depending on the mineral composition of the sample (intrinsic luminescence) and on the number and nature of defects and impurities in the material (extrinsic luminescence). Quartz can exhibit several different $\mathrm{CL}$ colors, ranging from bright blue to red, brown, or nearly nonluminescent. Several studies have attempted to use CL color and intensity as a provenance tool (e.g., Zinkernagel 1978; Seyedolali et al. 1997; Boggs et al. 2002; Bernet and Bassett 2005), but there is too much overlap in the color ranges to make this a reliable quantitative method (Boggs et al. 2002). Furthermore, the crystallographic orientation of quartz grains can have a significant effect on $\mathrm{CL}$ color (Walderhaug and Rykkje 2000). In general, volcanic quartz has blue CL color, whereas plutonic, metamorphic, and hydrothermal quartz CL colors range from blue to red (Marshall 1988; Boggs et al. 2002).

The CL emission of quartz depends on many factors such as the degree of ordering in the crystal lattice; vacant lattice sites; trace amounts of activators such as $\mathrm{Fe}^{3+}, \mathrm{Al}^{3+}, \mathrm{H}^{+}, \mathrm{Li}^{+}, \mathrm{Na}^{+}, \mathrm{K}^{+}$, and $\mathrm{Ti}^{4+}$; water content; or damage resulting from radiation, strain, or shock (Marshall 1988; Ramseyer and Mullis 1990; Perny et al. 1992). Recently, many studies have focused on the causes of CL intensity differences in quartz (Rusk and Reed 2002; Landtwing and Pettke 2005; Rusk et al. 2006) and of specific emission bands in the CL spectra of quartz and other forms of $\mathrm{SiO}_{2}$ (Ramseyer and Mullis 1990; Perny et al. 1992; Stevens Kalceff and Phillips 1995; Stevens Kalceff et al. 2000; Götze et al. 2001; Trukhin et al. 2003, 2004; Götze and Kempe 2008; Stevens Kalceff 2009). Common emission bands are around $340 \mathrm{~nm}$ (Al and $\mathrm{Li}$ impurities), $420 \mathrm{~nm}$ (intrinsic emission), and 620-650 $\mathrm{nm}$ (nonbridging oxygen hole center, NBOHC) (Stevens Kalceff and Phillips 1995; Stevens Kalceff et al. 2000; Götze et al. 2001), but many more are described in the literature. The relative intensities of the dominant emission bands in the visible light range $(380-700 \mathrm{~nm})$ determine the $\mathrm{CL}$ color that is perceived by the eye (Götze et al. 2001).

Shocked quartz is generally blue luminescent, with an additional emission band at 630-650 nm (Ramseyer et al. 1992; Ramseyer and Mullis 2000; Trepmann et al. 2005; Götte 2009; Okumura et al. 2009; Kayama et al. 2010), although the 630-650 $\mathrm{nm}$ band was not observed in experimentally shocked quartzite (Gucsik et al. 2003).

\section{RESULTS}

\section{Grayscale Cathodoluminescence}

In the limited wavelength grayscale SEM-CL images (Fig. 2), PDFs appear as well-defined, narrow darker lines that are nonluminescent in contrast to the host quartz grains, which are lighter in the CL images. Usually, the PDFs are straight and of constant thickness (Fig. 2a, b, and e), but in some grains, they appear slightly curved and show slight thickness variations (Fig. 2c and d). In all of these grains, multiple sets of PDFs are present (at least three, often four or more), and they are very closely and regularly spaced, thicker, and have slightly wavy edges. PDFs from different impact structures show the same CL characteristics; only in the Vredefort samples (Fig. 2f) no clear PDFs are visible in the grayscale images.

Tectonic deformation lamellae in grayscale SEM-CL images (Fig. 3) can either be more luminescent than the host quartz grain or nonluminescent. In general, the lamellae have slightly wavy features with a varying 


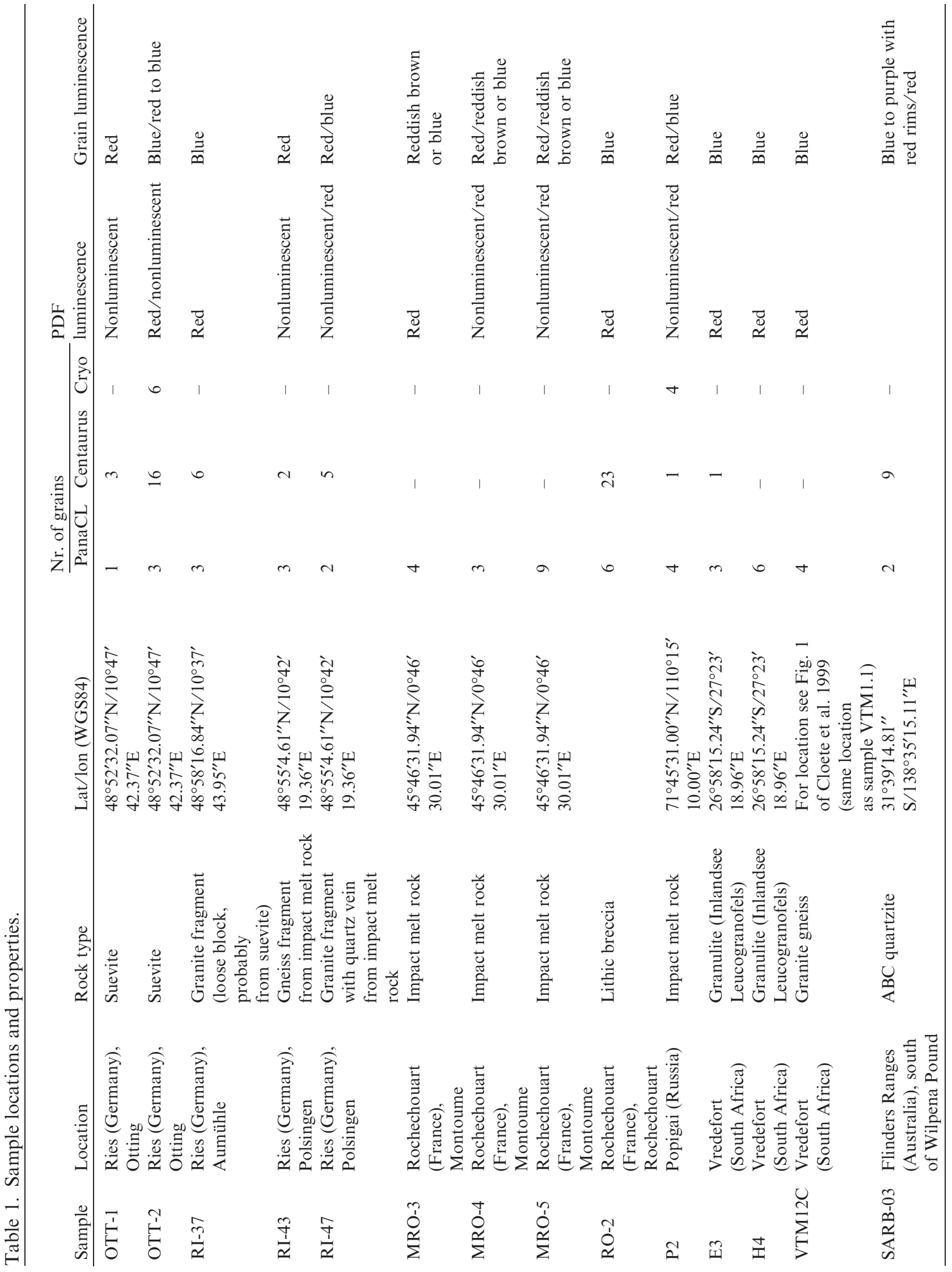




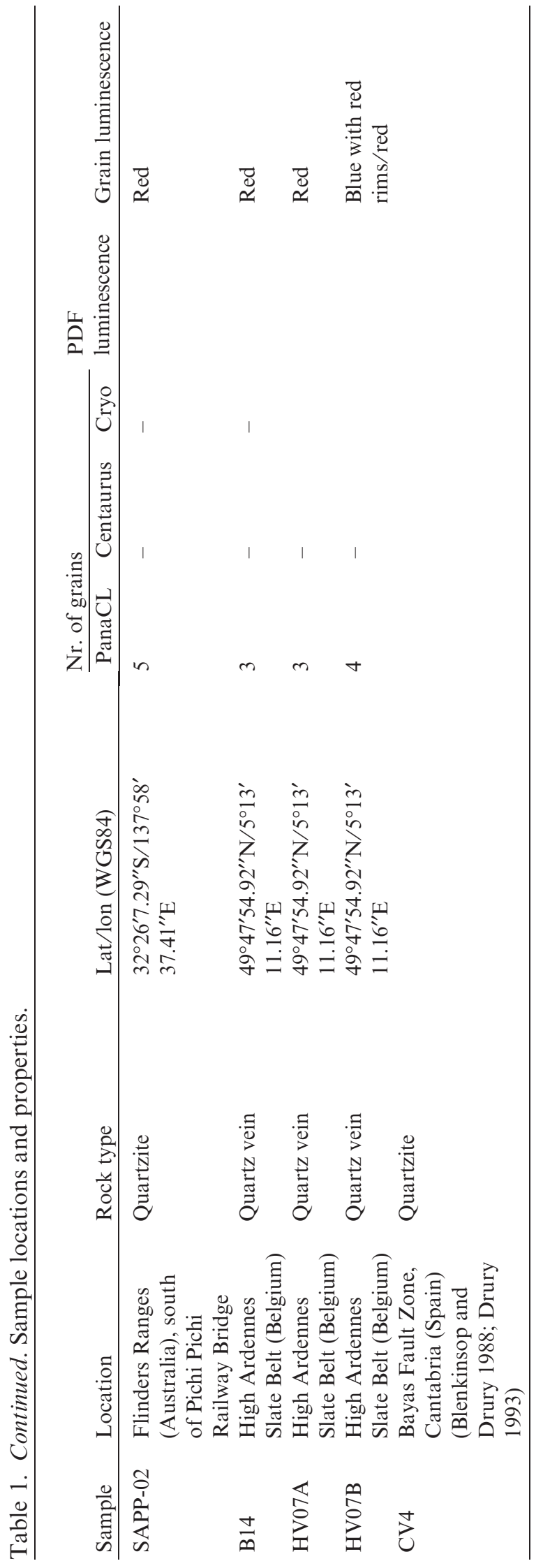



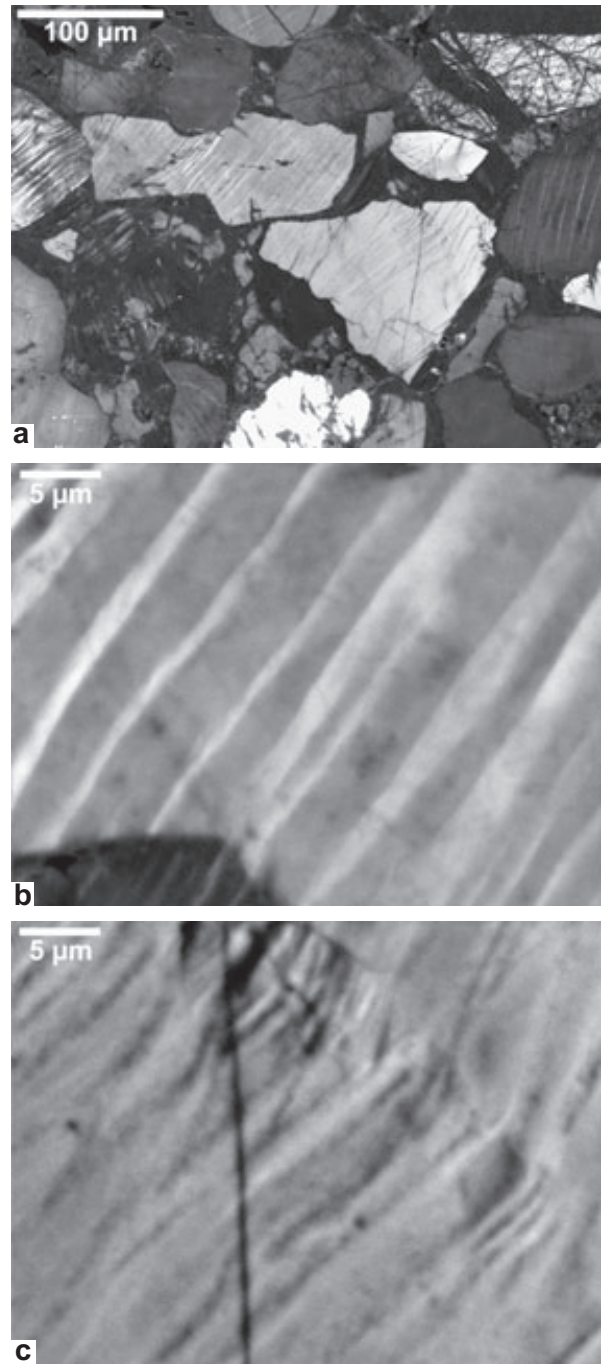

Fig. 3. a) Limited wavelength CL images of tectonic deformation lamellae from the Flinders Ranges. b) Close-up of the grain above and left of the center in a. c) Close-up of the grain below and right of the center in a.

thickness; they are thicker and much less well-defined than the PDFs in Fig. 2.

\section{Composite Color Cathodoluminescence}

In terms of shape and thickness, PDFs in the composite color SEM-CL images (Fig. 4) are identical to the limited wavelength images (Fig. 2). However, it is evident that the PDFs are usually luminescent and mainly emit red light (Fig. 4a-f, and i) which differs from the $\mathrm{CL}$ information in the grayscale images shown in Fig. 2. This is true for most PDFs, including the Vredefort samples (Fig. 4e and f), and in host quartz grains, which have different CL colors, ranging from red and brown to purple and blue. The red emission of the
PDFs becomes brighter with increasing scanning time and after repeated scanning with the electron beam, making them more easily discernable. Only in highly shocked grains with multiple sets of closely spaced PDFs are the lamellae nonluminescent (Fig. $4 \mathrm{~g}$ and h). This is the case in the grains that show more, thicker, less straight, and more sets of PDFs in limited wavelength images. Fig. $4 \mathrm{~g}$ also shows that partly red, partly nonluminescent PDFs occur (bottom right, SW-NE trending set). Red-luminescent PDFs usually occur in violet to blue-luminescent host quartz (Fig. 4a, b, e, f, and i), although also in Rochechouart grains, reddishbrown host quartz is observed (Fig. 4c and d). Nonluminescent PDFs most often occur in redluminescent host quartz (Fig. 4h), but in some cases, the host quartz shows both red and blue luminescent parts (Fig. 4g).

Composite color images of tectonic deformation lamellae (Fig. 5) are very similar to the limited wavelength images shown in Fig. 4, but differ very much from the color images of PDFs. Although shape and thickness alone are clearly sufficient to distinguish between tectonic deformation lamellae and PDFs, the CL color information further emphasizes the different appearance of the two microstructures. While PDFs are consistently red or nonluminescent, tectonic deformation lamellae show a range of colors from blue to red. It is not always clear where host quartz and tectonic lamella begin or end, or even which part of the grain should be defined as "grain" or "lamella." Due to their variable $\mathrm{CL}$ emission and the vague boundaries between lamellae and host quartz, in both grayscale and color CL images, it is very difficult to accurately define and measure the spacing and thickness of tectonic deformation lamellae. PDFs on the other hand have sharp boundaries, and a clear distinction can be made between PDF and host quartz, making accurate measurements of their (apparent) spacing and thickness possible.

Table 2 summarizes the characteristics of both PDFs and tectonic deformation lamellae in CL images.

\section{Secondary Electron Imaging}

Secondary electron images of two tectonically deformed and six shocked quartz grains are shown in Fig. 6. Tectonic deformation lamellae (Fig. 6a and 6b) are barely detectable in SE images. In some grains, they show up as more or less linear, but relatively broad (compared with decorated PDFs), traces of fluid inclusions (Fig. 6b, through the center from top left to bottom right). PDFs are only visible in SE images when they are decorated; these PDFs show up as strictly linear traces of tiny holes or fluid inclusions (Fig. 6d). It is clear from Fig. $6 \mathrm{c}$ that undecorated PDFs cannot be 

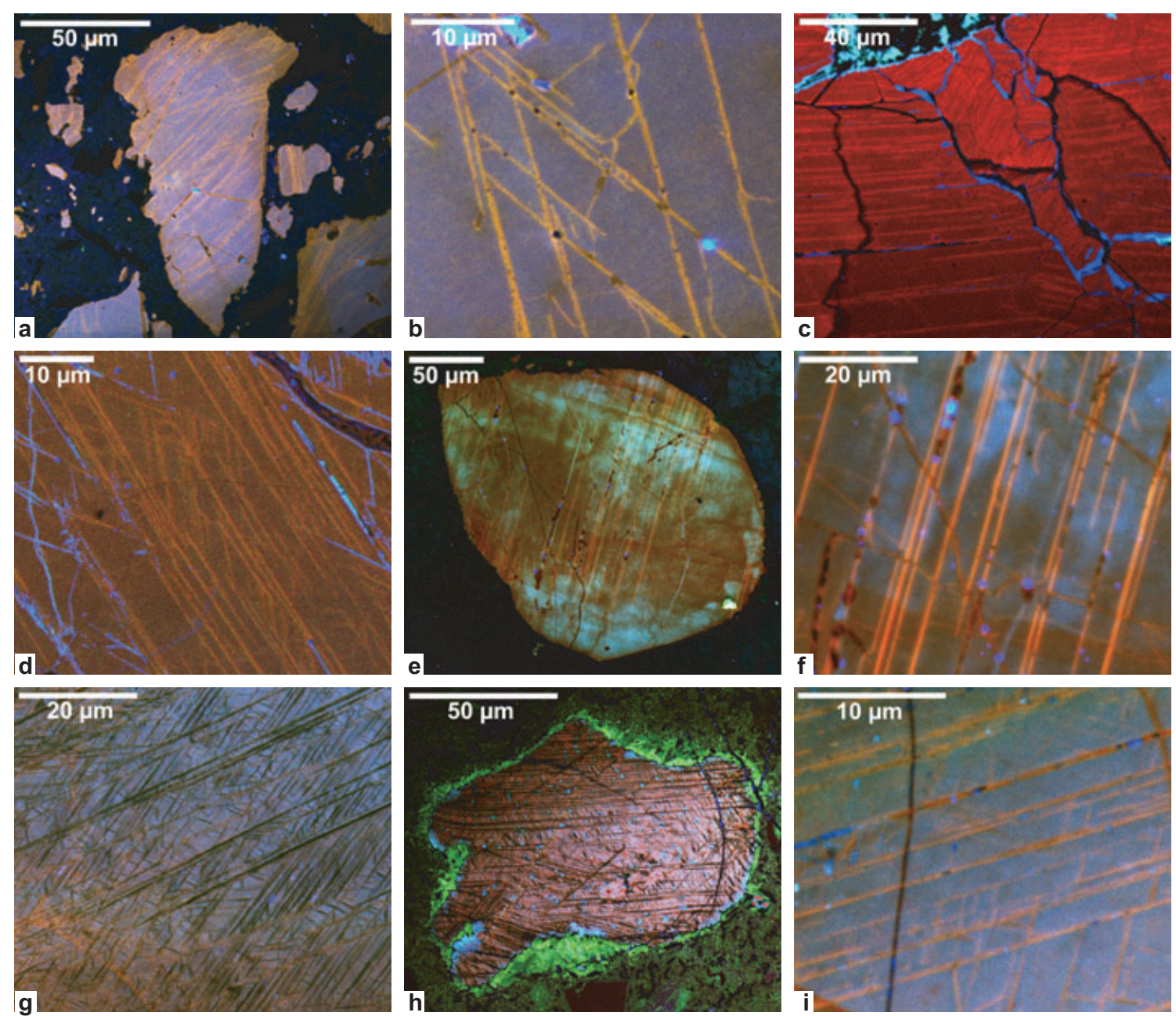

Fig. 4. Composite color CL images of PDFs from a) Rochechouart-same grain as in Fig. 1b. b) Rochechouart-higher magnification image of the grain in Fig. 2e. c) Rochechouart-higher magnification image of the grain in Fig. 1c. d) Rochechouart. e) Vredefort - same grain as in Fig. 2f. f) Vredefort-higher magnification of the grain in Fig. 4e and 2f. g) Ries. h) Popigai. i) Popigai. In all samples, including those from Vredefort, PDFs are clearly visible as either red or nonluminescent linear features. Bright blue-luminescent spots are caused by remains of aluminum oxide polishing grains.

recognized in SE images (compare Fig. 6c to Fig. 4d, where the same grain shows multiple sets of PDFs in the color CL image that are invisible in the SE image). In some grains where many sets of closely spaced PDFs are present, the PDFs are not decorated by small holes, but are partly open features (as in Fig. 6e). It seems that these partly open PDFs are always of the nonluminescent type, whereas both "normal" decorated and undecorated PDFs are red luminescent (in between the fluid inclusions, in the case of decorated PDFs). The nonluminescence occurs not only in the open parts of these PDFs, where there is no material to produce a $\mathrm{CL}$ signal but also in the rest of the lamellae (compare Fig. $4 \mathrm{~g}$ and 6e). Therefore, there is a genuine lack of $\mathrm{CL}$ signal in these PDFs.

\section{Cryogenic Composite Color Cathodoluminescence}

Figure 7 shows composite color images of the same grains, recorded at room temperature and at $-140{ }^{\circ} \mathrm{C}$ or $-170{ }^{\circ} \mathrm{C}$. Using the liquid nitrogen-cooled cryostage, the intensity of the CL emission strongly increases, especially in the blue and green color ranges. In most cases, the overall color characteristics of the shocked quartz grains remain the same: red-luminescent and nonluminescent PDFs occur, although the CL color of the host quartz often changes slightly at cryogenic temperature. However, in some grains that contain the nonluminescent type of PDFs at room temperature, red-luminescent PDFs appear at cryogenic temperatures that are not visible at room temperature (compare Fig. 4h with Fig. 7f and 7i). 
For many grains, the image quality is better at room temperature than at cryogenic temperatures. As a result of the extreme increase in intensity of the blue emission, there is less detail in the cryo-CL images (compare Fig. $7 \mathrm{~g}$ and h, or Fig $4 \mathrm{~h}$ and 7 f).

\section{DISCUSSION}

\section{Distinction Between Planar Deformation Features and Tectonic Deformation Lamellae}

The most important characteristics of PDFs and deformation lamellae are summarized in Tables 1 and 2 . Our results show that CL imaging is a very promising method to distinguish between shock and tectonic deformation lamellae, even on a visual basis alone. In cases where only one or two sets of lamellar microstructures are present, which could lead to misidentification in a light microscope, the CL characteristics of the structures clearly show whether they are PDFs or tectonic deformation lamellae (Figs. 2-5): PDFs are thin, straight lines that are dark in grayscale $\mathrm{CL}$ images, and red or nonluminescent in composite color CL images, whereas tectonic deformation lamellae are less well defined, thicker, and slightly wavy, with varying thickness, and can show varying CL colors in composite color images.

The physical basis of the difference in CL emission between shocked and tectonically deformed grains remains unclear, and requires further research into the relationship between the $\mathrm{CL}$ emission and the nature of the different microstructures. However, even without knowing the exact cause of the CL signal, SEM-CL imaging appears to be a useful technique to distinguish between tectonic and shock lamellae, and to identify PDFs in quartz.

Spacing and (apparent) thickness of planar microstructures in quartz have been mentioned as characteristic features to distinguish between tectonic and shock lamellae (Stöffler and Langenhorst 1994; Grieve et al. 1996; French and Koeberl 2010), but are in practice not often used quantitatively. In general, tectonic deformation lamellae are thicker, more widely spaced, and usually slightly curved, whereas PDFs are extremely thin, closely spaced, and straight (Alexopoulos et al. 1988; Lyons et al. 1993). However, these are not definitive criteria; a range of different types of tectonic deformation lamellae has been recognized (Christie and Raleigh 1959; White 1973; Christie and Ardell 1974; Drury 1993; Vernooij and Langenhorst 2005). For both PDFs and tectonic deformation lamellae, there are many cases in which spacing, thickness, and straightness deviate from the "standard" values. Even in a relatively small sample set such as ours, these characteristics show considerable variation, which is obvious from Fig. 2 to 5 .
Whereas the PDF spacing depends on the impact pressure, the spacing of tectonic deformation lamellae depends on stress level (Koch and Christie 1981). Tectonic lamellae may occur that are as closely spaced as PDFs (see for example the tectonic lamellae in Fig. 5d, e, and f). Furthermore, spacing and thickness measurements will depend on the imaging method used; in SEM-CL images, for example, more and thinner individual lamellae can be recognized than in light microscopic images, and thus the results of spacing and thickness measurements could differ if the size and spacing of the PDFs are below the spatial resolution for the imaging method used. The spatial resolution of a standard light microscope is theoretically limited to approximately 200-400 $\mathrm{nm}$ (Nesse 2004), but is worse in practice. It is known from TEM measurements that many PDFs and some types of tectonic deformation lamellae are thinner than this limit (McLaren et al. 1970; Langenhorst 1994; Stöffler and Langenhorst 1994), and some of these lamellae, therefore, will not be detected in a light microscope. As already mentioned in the section Composite Color Cathodoluminescence, it is questionable whether it is at all possible to perform reliable measurements of spacing and thickness on tectonic deformation lamellae. Tectonic deformation lamellae are not as clearly defined as PDFs. In CL images, it is not always evident which part of the grain is lamella and which part is host quartz (see for example Fig. 3c, 5b, 5c, and 5e). McLaren et al. (1970) also pointed out that in a light microscope, tectonic deformation lamellae are most easily observed when the microscope is focused on the upper surface of the thin section, and that when the lamellae are exactly in focus (which would be required for accurate thickness measurements), they are almost invisible. Thus, measurements on tectonic deformation lamellae are difficult and unreliable.

The presence of multiple, differently oriented sets of (indexed) planar features in a quartz grain of course remains a good indicator for shock, but in cases where light microscopy shows only one or two sets of lamellae, and when it is not immediately obvious whether these are shock or tectonic lamellae, CL imaging can distinguish between the two. In addition to the shape criteria described above, CL images often show more sets of PDFs than can be observed in light microscopy. This is readily seen when comparing, for example Fig. 1c and Fig. 4c, or Fig. 1b and Fig. 4a, which show the same grain in a light microscopic and color CL image, respectively.

Filtered, color, and cryo-CL imaging and CL spectroscopy can all provide extra information on the nature of planar microstructures in quartz. However, unfiltered grayscale CL images will, in many cases, be sufficient to distinguish PDFs from tectonic deformation lamellae and show features that are unclear in light microscopy. 

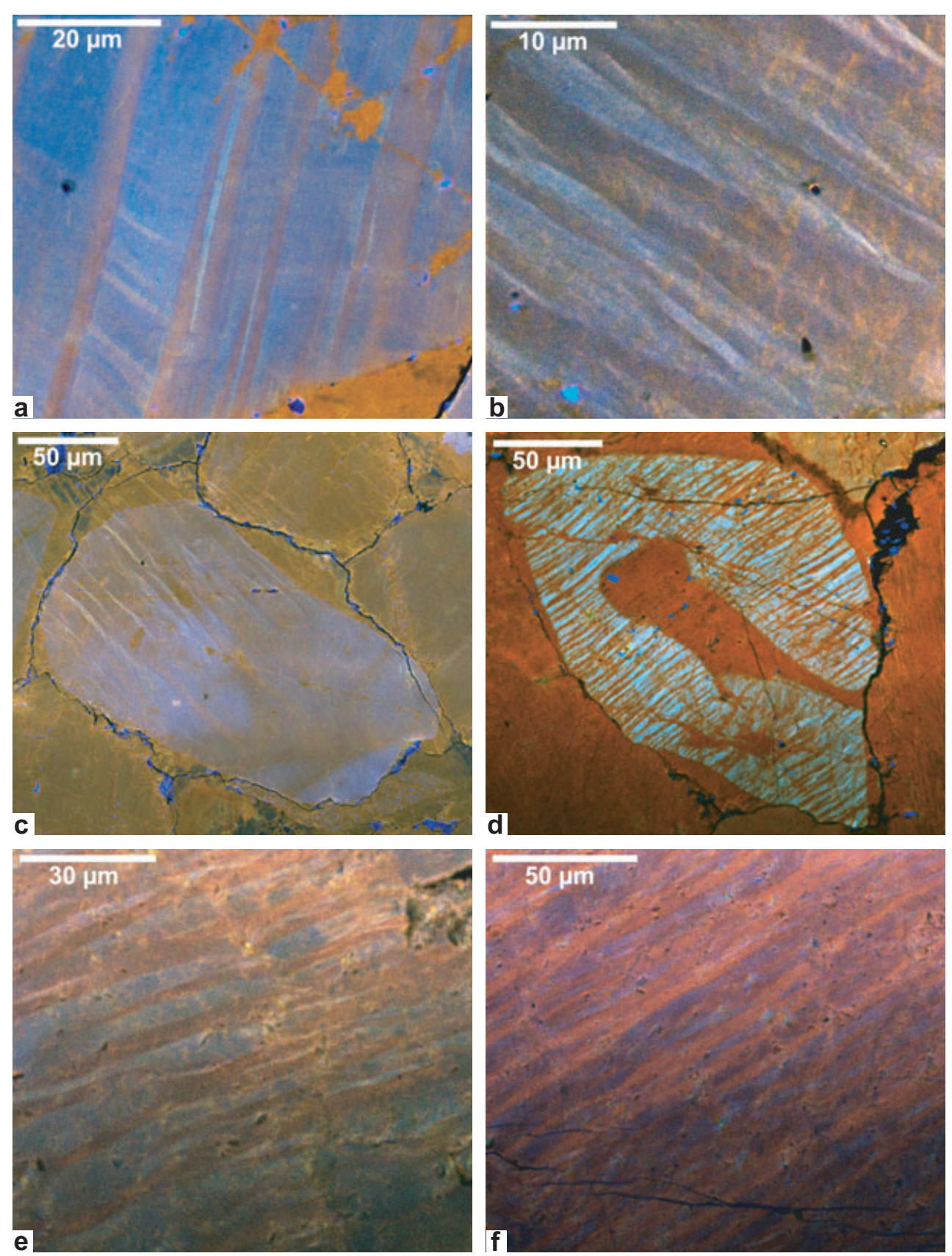

Fig. 5. Composite color CL images of tectonic deformation lamellae from Flinders Ranges (a-same grain as in Fig. 1d; b and c), Cantabria (d), and the Ardennes (e and f). Bright blue-luminescent spots are caused by remains of aluminum oxide polishing grains.

All our shocked samples are from impact structures in predominantly crystalline, nonporous target rocks. As a result of the porosity of sedimentary target rocks, the shock wave energy is distributed much more heterogeneously than in crystalline targets. As a result, shock effects representative of different shock stages in the classification for nonporous rock types can occur together in porous rocks (Grieve et al. 1996). However, the same types of shock effects occur, and there is essentially no structural difference between PDFs in quartz grains from crystalline (nonporous) or from sedimentary (porous) target rocks (Kieffer 1971; Kieffer et al. 1976). We therefore do not expect that the CL characteristics from PDFs in quartz from sedimentary rocks differ so much from those in crystalline rocks, and that the distinction between PDFs and tectonic 
Table 2. Cathodoluminescence characteristics for planar deformation features and tectonic deformation lamellae.

\begin{tabular}{lll}
\hline & Planar deformation features & Tectonic deformation lamellae \\
\hline CL color & Red/non & Red/blue \\
Number of sets & (Usually) multiple & Usually one, rarely two \\
"Sharpness" & Very well defined & Hard to distinguish lamellae from host quartz \\
Thickness & (Usually) thin & (Usually) much thicker \\
Spacing & Variable, but usually closely spaced & Closely spaced \\
Straightness & Straight & Slightly curved, subplanar \\
\hline
\end{tabular}

deformation lamellae becomes impossible. Future research is needed to show how the extra heat production involved in impacts into porous rocks might affect the CL emission of (parts of) shocked quartz grains.

\section{Cathodoluminescence Characteristics of Planar Deformation Features in Quartz}

\section{Cryo-Cathodoluminescence}

In contrast to many other minerals, such as feldspars, calcite, or zircons, quartz does not exhibit high intensity $\mathrm{CL}$ emission at room temperature. At temperatures below -80 to $-100{ }^{\circ} \mathrm{C}$, the $\mathrm{CL}$ emission of quartz shows a dramatic increase in intensity by factors of 100-1000 (Marshall 1988) so to get the highest intensity signal, CL work is often carried out at low temperature. In our low temperature comparison, the intensity of the CL emission strongly increased, as expected, especially in the blue and green range. However, the overall results at cryogenic temperatures were the same as those found at room temperature: both red- and nonluminescent PDFs are present, and in most cases also the CL color of the host quartz does not change significantly. These results show that, although cryo-CL does give a higher intensity $\mathrm{CL}$ emission, cryo is not required to image shocked quartz grains and identify PDFs. On the contrary, as Boggs et al. (2001) already observed, the quality of the CL images is often better at room temperature than at cryogenic temperatures. Although cryo-CL can often provide extra information, even the simplest method of SEM-CL imaging, at room temperature, produces high quality images that are sufficient to identify PDFs in quartz and distinguish them from tectonic deformation lamellae.

\section{Cathodoluminescence of Shocked Quartz}

Boggs et al. (2001) reported that PDFs can be imaged with SEM-CL methods, and concluded that PDFs are visible in CL images because they are nonluminescent in contrast to the host quartz grain. Our results show that the latter is not the case; in fact, most PDFs do emit light, mostly in the red to infrared wavelength range (595-850 nm, red filter). PDFs often appear nonluminescent in (panchromatic) CL images, because the intensity of the (usually) blue light emitted by the surrounding quartz is often so much higher than the intensity of the signal coming from the material in the PDFs. In the case of Boggs et al. (2001), the apparent nonluminescence of the PDFs might also be a result of the CL detector they use, which has a detection range of about 185-700 nm, and detects (part of) the ultraviolet and the complete blue wavelength range, but does not detect all of the red range $(620-750 \mathrm{~nm})$, and none of the infrared wavelengths. The PDFs could appear nonluminescent because of the low intensity of the CL signal emitted by the PDFs and the limited range of the detector, although this would depend on the specific wavelength of the CL emission of the PDFs. In the images recorded with our blue-sensitive limited wavelength $\mathrm{CL}$ detector, PDFs are dark because they emit red light, which is not detected, and therefore the structures appear to be nonluminescent. Several studies have shown that shocked quartz is usually blue luminescent, with an additional emission band at 630 $650 \mathrm{~nm}$ (Ramseyer et al. 1992; Ramseyer and Mullis 2000; Trepmann et al. 2005; Götte 2009; Okumura et al. 2009; Kayama et al. 2010). The red-luminescent PDFs observed in our samples could (partly) be the source of this band.

The two types of CL behavior observed in PDFs (red to infrared or nonluminescent) are possibly related to shock intensity. Nonluminescence of PDFs only occurs in grains with multiple sets of closely and regularly spaced, thicker PDFs (Fig. 4g and h), which indicate high shock pressure (Grieve et al. 1996; Ferrière et al. 2008). Okumura et al. (2009) found that shocked quartz grains from the Ries crater show the usual emission bands with maxima around $385 \mathrm{~nm}$ (violet) and around $650 \mathrm{~nm}$ (red). The $650 \mathrm{~nm}$ band is observed independent of shock pressure, whereas the $385 \mathrm{~nm}$ band dissappears in more highly shocked grains. This seems to be in line with the observation that nonluminescent PDFs usually occur in highly shocked, red-luminescent quartz grains. Red CL emission of PDFs is seen in grains with a lower number of sets of PDFs, which are more widely and less regularly spaced and are therefore interpreted as the result of lower shock pressure.

Most of the PDFs from the Vredefort impact structure occur in single sets and are of the basal, Brazil 

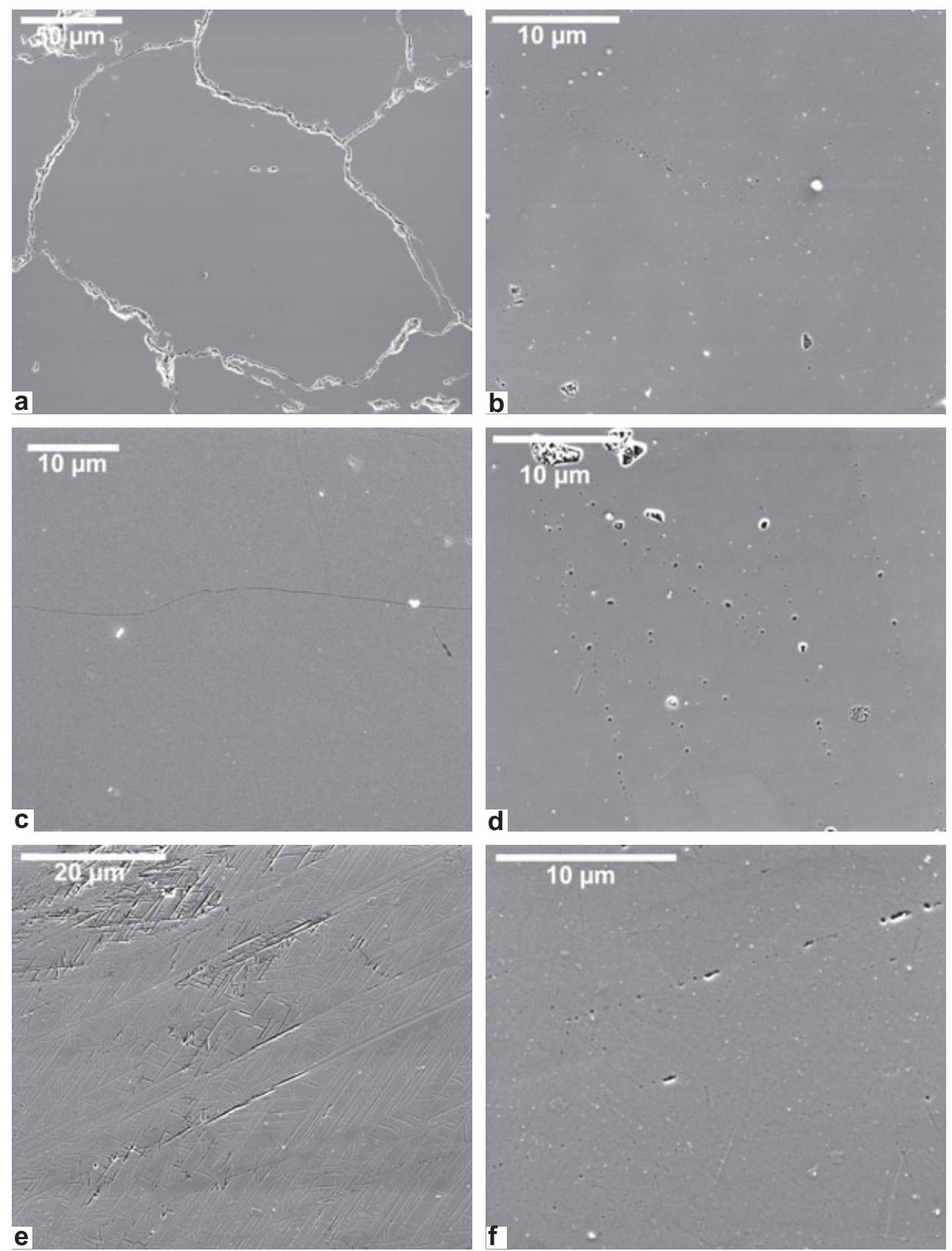

Fig. 6. Secondary electron images of a) Tectonic deformation lamellae from Flinders Ranges-same grain as in Fig. 5c. b) Tectonic deformation lamellae from Flinders Ranges - same grain as in Fig. 5b. c) Undecorated PDFs from Rochechouart-same grain as in Fig. 1c and 4c. Note that the PDFs in this grain can be seen in both light microscopic and CL images, but are invisible in this SE image. d) Decorated PDFs from Rochechouart - same grain as in Fig. 2e and 4b. e) PDFs from Ries-same grain as Fig. 4f. Black linear features in this image are open PDFs; other contrast is probably the result of some slight orientation contrast detected. f) PDFs from Popigai-same grain as in Fig. 4g. Some PDFs are decorated, but most are not (note that they can be recognized in the CL image in Fig. 4g).

twin type (Carter 1965; Grieve et al. 1990; Leroux et al. 1994). In our Vredefort samples, we observed only grains with one set of PDFs so it is likely that most of these are basal PDFs. It is striking that the characteristic red CL emission is observed in features that have a fundamentally different structure: in PDFs that are considered amorphous (Ries) as well as in basal, Brazil twin type PDFs (Vredefort) and decorated PDFs (Rochechouart, Popigai). An explanation for this is not apparent from the $\mathrm{CL}$ images alone and will require further research into the 

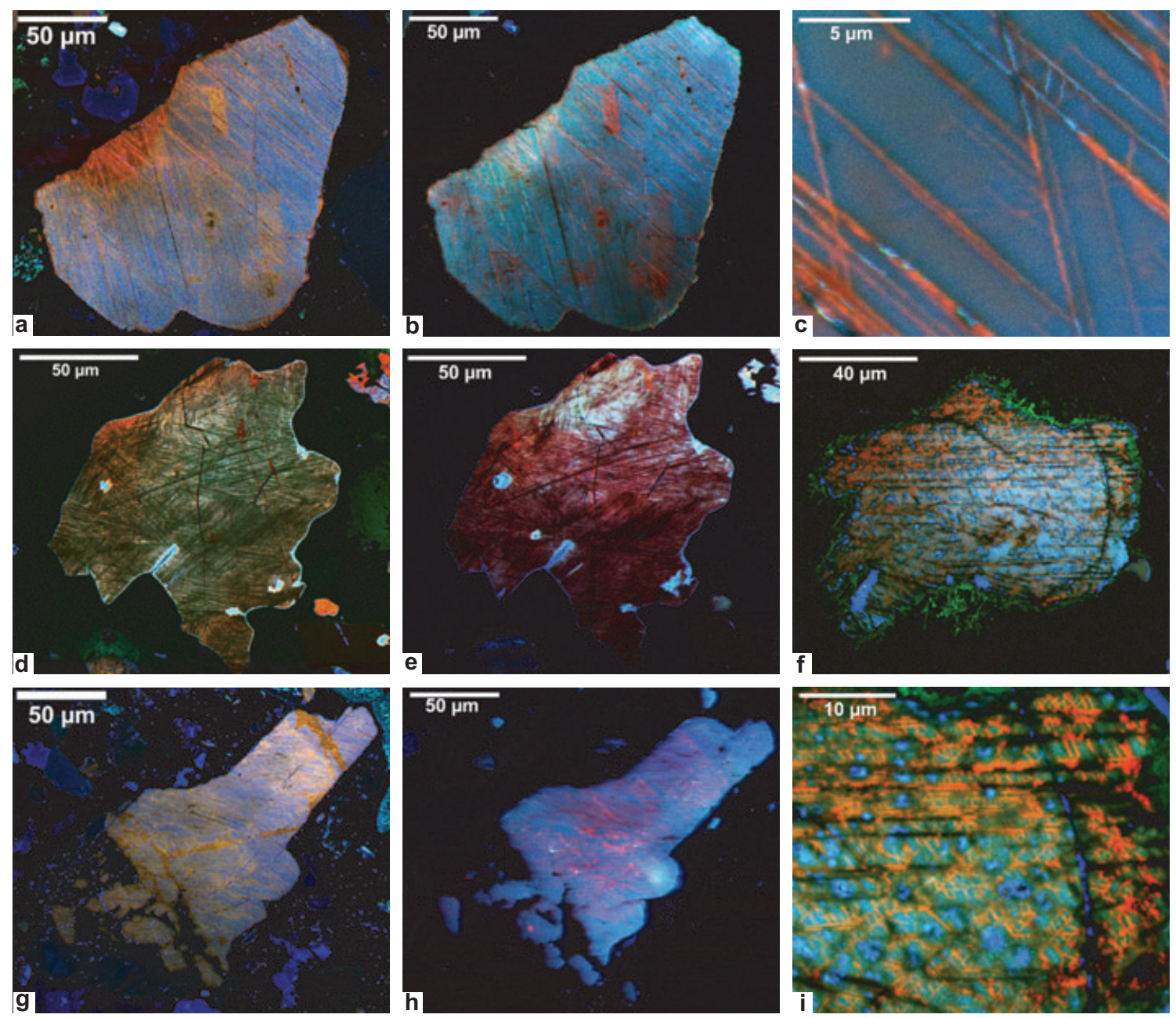

Fig. 7. Composite color CL images recorded at room temperature (RT) and at cryogenic temperatures. a) Shocked quartz grain from the Ries crater, showing red-luminescent PDFs, RT. Red patches are beam damage from earlier scanning. Same grain as in Fig. 2a. b) Same grain as in a, $-140{ }^{\circ} \mathrm{C}$. c) Higher magnification of the grain in a and $\mathrm{b},-140{ }^{\circ} \mathrm{C}$. Small irregularities in the PDFs are a relict of slight charging of the sample. d) Shocked quartz grain from the Ries crater, showing nonluminescent PDFs, RT. e) Same grain as in $\mathrm{d},-170^{\circ} \mathrm{C}$. f) Shocked quartz grain from the Popigai crater, same grain as in Fig. $4 \mathrm{~h},-170{ }^{\circ} \mathrm{C}$. At RT, this grain contains nonluminescent PDFs, and the host quartz is red luminescent. At $-170{ }^{\circ} \mathrm{C}$ also, red-luminescent PDFs appear and the host quartz shows more blue CL. g) Shocked quartz grain from the Ries crater, showing red-luminescent PDFs, RT. h) Same grain as in $\mathrm{g},-170{ }^{\circ} \mathrm{C}$. i) Higher magnification image of the grain in $\mathrm{f},-170{ }^{\circ} \mathrm{C}$. Bright blue spots in these images are remains of polishing grains.

exact nature of the defects, composition, or water content variations that might cause the typical red CL signal of PDFs.

\section{Possible Causes of the CL Behavior of Planar Deformation Features and Difference between Red-and Nonluminescent PDFs}

Several causes of red CL emission in quartz are mentioned in the literature. High water content or low $\mathrm{Ti} / \mathrm{Fe}$ ratio can result in a red $\mathrm{CL}$ emission (Marshall 1988). Substitutional incorporation of $\mathrm{Fe}^{3+}$ into the quartz lattice probably gives rise to an emission band around $705 \mathrm{~nm}$ (red to infrared) (Götze et al. 2001). Fitting et al. (2001) observed a red peak (around $650 \mathrm{~nm}$ ) in the $\mathrm{CL}$ spectrum of $\mathrm{SiO}_{2}$ glass, indicating that also amorphous $\mathrm{SiO}_{2}$ is capable of producing red CL (although, of course, CL color cannot prove anything on crystal structure). The most important red CL peak is the common $620-650 \mathrm{~nm}$ emission band in quartz. It consists of two overlapping components at $620 \mathrm{~nm}$ and at $650 \mathrm{~nm}$, and can be caused by an oxygen vacancy or a nonbridging oxygen hole center (NBOHC, $\equiv$ Si-O, a dangling oxygen bond) (Stevens Kalceff and Phillips 1995; Stevens Kalceff et al. 2000; Götze et al. 
2001). Different precursors for the NBOHC have been proposed that influence the band position. Among these precursors are hydrogen and sodium impurities, hydroxyl groups $(\equiv \mathrm{Si}-\mathrm{OH})(620 \mathrm{~nm})$, peroxy linkages $(\equiv \mathrm{Si}-\mathrm{O}-\mathrm{O}-\mathrm{Si} \equiv)(650 \mathrm{~nm})$, and strained silicon-oxygen bonds $(\mathrm{Si}-\mathrm{O})(650 \mathrm{~nm})$ (Stevens Kalceff and Phillips 1995; Götze et al. 2001).

The $650 \mathrm{~nm}$ emission increases during electron bombardment (Götze et al. 2001), which is an indication that this might be the emission of the red-luminescent PDFs, as they become brighter after repeated scanning with the electron beam. Furthermore, this emission band is commonly observed in shocked quartz grains (Ramseyer et al. 1992; Ramseyer and Mullis 2000; Trepmann et al. 2005; Götte 2009; Okumura et al. 2009; Kayama et al. 2010). Götte (2009) attributed the presence of a 630-650 nm emission band in shocked quartz from the Siljan and Araguainha craters to thermal breaking of $\mathrm{OH}$ groups, which are incorporated in the quartz. However, according to Stevens Kalceff et al. (2000), the emission related to the NBOHC with $\mathrm{OH}$ precursor is at $620 \mathrm{~nm}$, and attenuates quickly under electron irradiation at room temperature. This does not fit our observation that the intensity of the emission in red-luminescent PDFs increases after repeated scanning.

Also, high water content or hydrogen impurities in the PDFs could explain the red luminescence, because $\mathrm{H}_{2} \mathrm{O}$ is much more soluble in the amorphous material within PDFs than in the adjacent crystalline quartz (Grieve et al. 1996). The occurrence of basal PDFs decorated with tiny fluid inclusions illustrates that along Brazil twin boundaries, water content might also be locally increased, giving rise to the same CL behavior for the two different types of PDF.

A final explanation for the red luminescence of PDFs might be strained silicon-oxygen bonds. It is possible that strained $\mathrm{Si}-\mathrm{O}$ bonds are present in the $\mathrm{SiO}_{2}$ within PDFs (or were present before annealing), where the crystal structure is disordered or (partly) destroyed by the shock wave. These strained bonds could form the precursors for NBOHCs. Also, basal, Brazil twin PDFs might contain strained silicon-oxygen bonds as a result of the high differential stresses that form these structures during the shock event. Although no bonds need to be broken to form this type of twin, there will be some strain at the twin boundary (McLaren et al. 1970).

Of course, the above interpretations remain rather speculative and measurements of CL spectra of the emission from the PDFs could provide valuable extra information for the interpretation of the PDF characteristics in CL images.

The difference in CL emission between the red- and nonluminescent PDFs could be caused by structural differences of the material within the PDFs, as a result of increasing shock pressure and temperature. As mentioned previously, the occurrence of multiple sets of nonluminescent PDFs per grain, their close and regular spacing, and thickness and slightly wavy boundaries, all indicate formation under high shock pressures (Langenhorst 1994; Ferrière et al. 2008). According to the model presented by Langenhorst (1994), the transformation of crystalline quartz to diaplectic quartz glass is a process in which the number of dense, amorphous PDFs increases with increasing shock pressure and temperature, until the whole grain consists of diaplectic glass, with fluidal glass (lechatelierite) only occurring when the residual (postshock) temperature is sufficiently high. Three phases occur during this process: (1) when both shock and postshock temperatures are below the melting point of quartz, extremely narrow, straight PDFs, consisting of a superheated, dense, amorphous phase, form by solid-state transformation, to compensate for crystal lattice incompatibilities at the shock wave propagation front; (2) at higher shock pressure, the shock temperature increases to just above the quartz melting temperature, and the PDFs are at a sufficiently high temperature to melt a small region of the adjacent crystalline quartz, resulting in thicker PDFs with more wavy boundaries; and (3) when, at even higher shock pressure, the shock temperature is significantly higher than the quartz melting temperature, the crystalline regions between the PDFs melt completely and the whole grain transforms into diaplectic quartz, which is quenched before complete decompression.

In this model, the red-luminescent (rhombohedral) PDFs could form during the first stage, when no melt is formed, but an amorphous phase in which the quartz lattice is disordered, but retains some of its structure. The $\mathrm{CL}$ emission centers that form during this stage must either survive postshock annealing, or be a secondary feature, because the red-luminescent PDFs are also observed in altered impact structures, such as the Rochechouart structure. During the second stage, the thicker, nonluminescent PDFs form, filled with quartz melt or diaplectic glass, because of the higher temperature associated with higher shock pressure. The complete destruction of the quartz crystal structure might result in nonluminescence of the material within the PDFs.

\section{CONCLUSIONS}

Both grayscale (limited wavelength) and composite color SEM-CL images provide strong criteria for distinction between planar deformation features and tectonic deformation lamellae in quartz, based on shape, thickness variability, and straightness, with different CL color signatures when color CL images are recorded. 
Color imaging is the most reliable technique, as it shows that PDFs occur as two main types: either red- or nonluminescent, whereas tectonic deformation lamellae show varying CL colors, ranging from blue to red. When color CL facilities are unavailable, grayscale CL images are, depending on the detection range of the CL detector, in most cases sufficient to distinguish shock from tectonic lamellae. Although the causes of the CL behavior of PDFs remain uncertain, SEM-CL imaging provides a promising qualitative method to identify PDFs in quartz and to distinguish them from tectonic deformation lamellae.

Acknowledgments-The authors thank Roald Tagle for providing the Popigai samples, Rodger Hart for the Vredefort samples, and Hervé van Baelen and Manuel Sintubin for the Ardennes samples. Prof. Pim van Wamel is thanked for field support at the Ries crater; Philippe Lambert for a great excursion around the Rochechouart crater. Matthijs de Winter provided invaluable support for the SEM work. Gill Pennock is gratefully acknowledged for her help and comments. Constructive reviews by Martin Schmieder and Arnold Gucsik, as well as comments from the editor, Gordon Osinski, have significantly improved the manuscript. This research is funded by the Netherlands Organization for Scientific Research (NWO).

Editorial Handling-Dr. Gordon Osinski

\section{REFERENCES}

Alexopoulos J. S., Grieve R. A. F., and Robertson P. B. 1988. Microscopic lamellar deformation features in quartz: Discriminative characteristics of shock-generated varieties. Geology 16:796-799.

Becker L., Poreda R. J., Basu A. R., Pope K. O., Harrison T. M., Nicholson C., and Iasky R. 2004. Bedout: A possible end-Permian impact crater offshore of Northwestern Australia. Science 304:1469-1476.

Bernet M. and Bassett K. 2005. Provenance analysis by singlequartz-grain SEM-CL/optical microscopy. Journal of Sedimentary Research 75:492-500.

Blenkinsop T. G. and Drury M. R. D. 1988. Stress estimates and fault history from quartz microstructures. Journal of Structural Geology 10:673-684.

Boggs S., Krinsley D. H., Goles G. G., Seyedolali A., and Dypvik H. 2001. Identification of shocked quartz by scanning cathodoluminescence imaging. Meteoritics \& Planetary Science 36:783-791.

Boggs S. Jr, Kwon Y.-I., Goles G. G., Rusk B. G., Krinsley D., and Seyedolali A. 2002. Is quartz cathodoluminescence color a reliable provenance tool? A quantitative examination. Journal of Sedimentary Research 72:408-415.

Böhm A. 1883. Ueber die Gesteine des Wechsels. Zeitschrift für Kristallographie, Mineralogie und Petrographie 5:197-214.

Carter N. L. 1965. Basal quartz deformation lamellae; a criterion for recognition of impactites. American Journal of Science 263:786-806.
Cavosie A. J., Quintero R. R., Radovan H. A., and Desmond E. M. 2010. A record of ancient cataclysm in modern sand: Shock microstructures in detrital minerals from the Vaal River, Vredefort Dome, South Africa. Geological Society of America Bulletin 122:1968-1980.

Christie J. M. and Ardell A. J. 1974. Substructures of deformation lamellae in quartz. Geology 2:405-408.

Christie J. M. and Raleigh C. B. 1959. The origin of deformation lamellae in quartz. American Journal of Science 257:385407.

Cloete M., Hart R. J., Schmid H. K., Drury M., Demanet C. M., and Sankar K. V. 1999. Characterization of magnetite particles in shocked quartz by means of electron- and magnetic force microscopy: Vredefort, South Africa. Contributions to Mineralogy and Petrology 137:232-245.

Cordier P. and Gratz A. J. 1995. TEM study of shock metamorphism in quartz from the Sedan nuclear test site. Earth and Planetary Science Letters 129:163-170.

Cordier P., Vrána S., and Doukhan J. C. 1994. Shock metamorphism in quartz at Sevetin and Susice (Bohemia)? A TEM investigation. Meteoritics 29:98-99.

Drury M. R. 1993. Deformation lamellae in metals and minerals. In Defects and processes in the solid state: Geoscience applications, edited by Boland J. N. and Fitz Gerald J. D. Amsterdam: Elsevier Science Publishers B. V. pp. 195-212.

Engelhardt W. V. and Bertsch W. 1969. Shock induced planar deformation structures in quartz from the Ries crater, Germany. Contributions to Mineralogy and Petrology 20:203-234.

Ernstson K. and Fiebag J. 1992. The Azuara impact structure (Spain)-New insights from geophysical and geological investigations. Geologische Rundschau 81:403-427.

Ferrière L., Koeberl C., Ivanov B. A., and Reimold W. U. 2008. Shock metamorphism of Bosumtwi Impact Crater rocks, shock attenuation, and uplift formation. Science 322:1678-1681.

Ferrière L., Koeberl C., and Reimold W. U. 2009. Characterisation of ballen quartz and cristobalite in impact breccias: New observations and constraints on ballen formation. European Journal of Mineralogy 21:203-217.

Ferrière L., Koeberl C., Libowitzky E., Reimold W. U., Greshake A., and Brandstätter F. 2010. Ballen quartz and cristobalite in impactites: New investigations. Geological Society of America Special Papers 465:609-618.

Fitting H.-J., Barfels T., Trukhin A. N., and Schmidt B. 2001. Cathodoluminescence of crystalline and amorphous $\mathrm{SiO}_{2}$ and $\mathrm{GeO}_{2}$. Journal of Non-Crystalline Solids 279:51-59.

French B. M. and Koeberl C. 2010. The convincing identification of terrestrial meteorite impact structures: What works, what doesn't, and why. Earth Science Reviews 98:123-170.

French B. M., Cordua W. S., and Plescia J. B. 2004. The Rock Elm meteorite impact structure, Wisconsin: Geology and shock-metamorphic effects in quartz. Geological Society of America Bulletin 116:200-218.

Glikson A. 2004. Comment on "Bedout: A possible endpermian impact crater offshore of Northwestern Australia." Science 306:613b.

Goltrant O., Leroux H., Doukhan J.-C., and Cordier P. 1992. Formation mechanisms of planar deformation features in naturally shocked quartz. Physics of The Earth and Planetary Interiors 74:219-240.

Götte T. 2009. Petrological modifications in continental target rocks from terrestrial impact structures: Evidence from 
cathodoluminescence. In Cathodoluminescence and its application in the planetary sciences, edited by Gucsik A. Berlin: Springer. pp. 45-60.

Götze J. and Kempe U. 2008. A comparison of optical microscope- and scanning electron microscope-based cathodoluminescence (CL) imaging and spectroscopy applied to geosciences. Mineralogical Magazine 72:909-924.

Götze J., Plötze M., and Habermann D. 2001. Origin, spectral characteristics and practical applications of the cathodoluminescence (CL) of quartz-A review. Mineralogy and Petrology 71:225-250.

Gratz A. J., Nellis W. J., Christie J. M., Brocious W., Swegle J., and Cordier P. 1992. Shock metamorphism of quartz with initial temperatures -170 to $+1000^{\circ} \mathrm{C}$. Physics and Chemistry of Minerals 19:267-288.

Gratz A. J., Fisler D. K., and Bohor B. F. 1996. Distinguishing shocked from tectonically deformed quartz by the use of the SEM and chemical etching. Earth and Planetary Science Letters 142:513-521.

Grieve R. A. F., Coderre J. M., Robertson P. B., and Alexopoulos J. 1990. Microscopic planar deformation features in quartz of the Vredefort structure: Anomalous but still suggestive of an impact origin. Tectonophysics 171:185-200.

Grieve R. A. F., Langenhorst F., and Stöffler D. 1996. Shock metamorphism of quartz in nature and experiment: II. Significance in geoscience (abstract). Meteoritics \& Planetary Science 31:6-35.

Gucsik A., Koeberl C., Brandstatter F., Libowitzky E., and Reimold W. U. 2003. Scanning electron microscopy, cathodoluminescence, and Raman spectroscopy of experimentally shock-metamorphosed quartzite (abstract). Meteoritics \& Planetary Science 38:1187-1197.

Kayama M., Nishido H., Endo Y., Sekine T., Gucsik A., and Ninagawa K. 2010. Estimation of shock pressure on quartz and alkali feldspar from Ries crater using cathodoluminescence spectroscopy (abstract \#5192). 73rd Annual Meeting of the Meteoritical Society: New York, USA. Meteoritics \& Planetary Science 45.

Kieffer S. W. 1971. Shock metamorphism of the Coconino Sandstone at Meteor Crater, Arizona. Journal of Geophysical Research 76:5449-5473.

Kieffer S. W., Phakey P. P., and Christie J. M. 1976. Shock processes in porous quartzite: Transmission electron microscope observations and theory. Contributions to Mineralogy and Petrology 59:41-93.

Koch P. S. and Christie J. M. 1981. Spacing of deformation lamellae as a palaeopiezometer. Transactions of the American Geophysical Union 62:1030.

Landtwing M. R. and Pettke T. 2005. Relationships between SEM-cathodoluminescence response and trace-element composition of hydrothermal vein quartz. American Mineralogist 90:122-131.

Langenhorst F. 1994. Shock experiments on pre-heated alphaquartz and beta-quartz: II. X-ray and TEM investigations. Earth and Planetary Science Letters 128:683-698.

Langenhorst F. and Deutsch A. 1994. Shock experiments on pre-heated alpha-quartz and beta-quartz: I. Optical and density data. Earth and Planetary Science Letters 125:407420.

Langenhorst F. and Deutsch A. 1996. The Azuara and Rubielos structures, Spain: Twin impact craters or alpine thrust systems? TEM investigations on deformed quartz disprove shock origin (abstract). 27th Lunar and Planetary Science Conference. pp. 725-726.

Langenhorst F., Kyte F. T., and Retallack G. J. 2005. Reexamination of quartz grains from the Permian-Triassic boundary section at Graphite Peak, Antarctica (abstract \#2358). 36th Annual Lunar and Planetary Science Conference: League City, Texas.

Leroux H. and Doukhan J.-C. 1993. Dynamic deformation of quartz in the landslide of Koefels, Austria. European Journal of Mineralogy 5:893-902.

Leroux H., Reimold W. U., and Doukhan J. C. 1994. A TEM investigation of shock metamorphism in quartz from the Vredefort Dome, South-Africa. Tectonophysics 230:223-239.

Lyons J. B., Officer C. B., Borella P. E., and Lahodynsky R. 1993. Planar lamellar substructures in quartz. Earth and Planetary Science Letters 119:431-440.

Marshall D. J. 1988. Cathodoluminescence of geological materials. Boston: Unwin Hyman. 146 p.

McLaren A. C., Turner R. G., Boland J. N., and Hobbs B. E. 1970. Dislocation structure of the deformation lamellae in synthetic quartz; a study by electron and optical microscopy. Contributions to Mineralogy and Petrology 29:104-115.

Nesse W.D. 2004. Introduction to optical mineralogy. Oxford: Oxford University Press, $348 \mathrm{p}$.

Officer C. B. and Carter N. L. 1991. A review of the structure, petrology, and dynamic deformation characteristics of some enigmatic terrestrial structures. Earth Science Reviews 30:149.

Okumura T., Gucsik A., Nishido H., Ninagawa K., and Toyoda S. 2009. Raman and cathodoluminescence spectroscopical microcharacterization of planar deformation features in shocked quartz from Ries impact crater (Germany). Geological Society of America, Abstracts with Programs, (41 No. 7): 308.

Perny B., Eberhardt P., Ramseyer K., Mullis J., and Pankrath R. 1992. Microdistribution of $\mathrm{Al}, \mathrm{Li}$, and $\mathrm{Na}$ in alpha quartz; possible causes and correlation with short-lived cathodoluminescence. American Mineralogist 77:534-544.

Poelchau M. H. and Kenkmann T. 2011. Feather features: A low-shock-pressure indicator in quartz. Journal of Geophysical Research 116:B02201.

Ramseyer K. and Mullis J. 1990. Factors influencing the shortlived blue cathodoluminescence of alpha-quartz. American Mineralogist 75:791-800.

Ramseyer K. and Mullis J. 2000. Geologic application of cathodoluminescence in silicates. In Cathodoluminescence in Geosciences, edited by Pagel M., Barbin V., Blanc P. and Ohnenstetter D. Berlin: Springer. pp. 177-191.

Ramseyer K., AlDahan A. A., Collini B., and Landström O. 1992. Petrological modifications in granitic rocks from the Siljan impact structure: Evidence from cathodoluminescence. Tectonophysics 216:195-204.

Retallack G. J., Seyedolali A., Krull E. S., Holser W. T., Ambers C. P., and Kyte F. T. 1998. Search for evidence of impact at the Permian-Triassic boundary in Antarctica and Australia. Geology 26:979-982.

Rusk B. and Reed M. 2002. Scanning electron microscopecathodoluminescence analysis of quartz reveals complex growth histories in veins from the Butte porphyry copper deposit, Montana. Geology 30:727-730.

Rusk B. G., Reed M. H., Dilles J. H., and Kent A. J. R. 2006. Intensity of quartz cathodoluminescence and trace-element 
content in quartz from the porphyry copper deposit at Butte, Montana. American Mineralogist 91:1300-1300.

Seyedolali A., Krinsley D. H., Boggs S., Ohara P. F., Dypvik H., and Goles G. G. 1997. Provenance interpretation of quartz by scanning electron microscope-cathodoluminescence fabric analysis. Geology 25:787-790.

Stevens Kalceff M. A. 2009. Cathodoluminescence microcharacterization of point defects in $\alpha$-quartz. Mineralogical Magazine 73:585-605.

Stevens Kalceff M. A. and Phillips M. R. 1995. Cathodoluminescence microcharacterization of the defect structure of quartz. Physical Review B 52:3122.

Stevens Kalceff M. A., Phillips M. R., Moon A. R., and Kalceff W. 2000. Cathodoluminescence microcharacterisation of silicon dioxide polymorphs. In Cathodoluminescence in Geosciences, edited by Pagel M., Barbin V., Blanc P. and Ohnenstetter D. Berlin: Springer. pp. 193-224.

Stöffler D. and Langenhorst F. 1994. Shock metamorphism of quartz in nature and experiment: I. Basic observation and theory. Meteoritics 29:155-181.

Surenian R. 1988. Scanning electron microscope study of shock features in pumice and gneiss from köfels (Tyrol, Austria). Geologisch-Palä ontologische Mitteilungen Innsbruck 15:135143.

Trepmann C. A. 2008. Shock effects in quartz: Compression versus shear deformation-An example from the Rochechouart impact structure, France. Earth and Planetary Science Letters 267:322-332.

Trepmann C. A. and Spray J. G. 2005. Planar microstructures and Dauphiné twins in shocked quartz from the Charlevoix impact structure, Canada. In Large Meteorite Impacts III, edited by Kenkmann T., Hörz F. and Deutsch A. Boulder, CO: Geological Society of America. pp. 315-328.

Trepmann C. A., Götte T., and Spray J. G. 2005. Impactrelated Ca-metasomatism in crystalline target-rocks from the Charlevoix structure, Quebec, Canada. The Canadian Mineralogist 43:553-567.

Trukhin A. N., Jansons J. L., Dyuzheva T. I., Lityagina L. M., and Bendeliani N. A. 2003. Luminescence of different modifications of crystalline silicon dioxide: Stishovite and coesite. Solid State Communications 127:415-418.

Trukhin A. N., Jansons J. L., and Truhins K. 2004. Luminescence of silica glass containing aluminum oxide. Journal of Non-Crystalline Solids 347:80-86.

Vernooij M. G. C. and Langenhorst F. 2005. Experimental reproduction of tectonic deformation lamellae in quartz and comparison to shock-induced planar deformation features (abstract). Meteoritics \& Planetary Science 40:1353-1361.

Vrána S. 1987. The Ševětín astrobleme, southern Bohemia, Czechoslovakia. Geologische Rundschau 76:505-528.

Walderhaug O. and Rykkje J. 2000. Some examples of the effect of crystallographic orientation on the cathodoluminescence colors of quartz. Journal of Sedimentary Research 70:545548.

Wegner M. W. and Christie J. M. 1983. Chemical etching of deformation sub-structures in quartz. Physics and Chemistry of Minerals 9:67-78.

White S. H. 1973. Deformation lamellae in naturally deformed quartz. Nature Physical Science 245:26-28.

Williams G. E. and Gostin V. A. 2005. Acraman-Bunyeroo impact event (Ediacaran), South Australia, and environmental consequences: Twenty-five years on. Australian Journal of Earth Sciences: An International Geoscience Journal of the Geological Society of Australia 52:607-620.

Zinkernagel U. 1978. Cathodoluminescence of quartz and its application to sandstone petrology. Contributions to Sedimentary Geology 8:1-69. 